Ann. Biol. anim. Bioch. Biophys., I962, 2 (4), 279-297.

\title{
POSSIBILITÉ DE FÉCONDATION DES CEUFS DE LAPINE ACTIVÉS PARTHÉNOGÉNÉTIQUEMENT
}

\author{
Marie-Claire CHALMEL \\ Station de Recherches de Physiologie animale, \\ Centre national de Recherches zootechniques, Jouy-en-Josas (Seine-et-Oise)
}

\section{SOMMAIRE}

Le refroidissement, à $0^{\circ} \mathrm{C}$ pendant $\mathrm{I}$ minute, de l'ovocyte de Lapine in vitro, permet d'obtenir l'émission du deuxième globule polaire et la formation d'un pronucléus haplö̈de dans environ la moitié des expériences.

Le refroidissement, à $10^{\circ} \mathrm{C}$ pendant 24 heures, permet l'activation de tous les ovocytes traités, la formation d'un noyau diploïde sans émission du deuxième globule polaire et la segmentation très régulière.

Ces ovocytes ainsi régulièrement activés ont permis d'étudier leur possibilité de fécondation subséquente.

Le pourcentage d'ovocytes activés et fécondés s'élève à $29 \mathrm{p}$. 10o in vitro et à $45 \mathrm{p}$. 10o après transplantation in vivo.

Ces travaux confirment les résultats déjà rapportés chez le Rat et la Lapine et compte tenu de la précision que nous ont permis les techniques in vitro, on doit considérer que l'hypothèse de BATAILLON de l'infécondabilité des œufs de Grenouille activés ne peut s'appliquer aux ovocytes de Lapine, car l'activation parthénogénétique chez la Lapine n'entraîne que l'activation des mécanismes de la segmentation et non systématiquement les réactions spécifiques de l'œuf activé : émission du deuxième globule polaire, résistance à l'action de certaines enzymes, blocage de la polyspermie.

L'évolution de ces cufs fécondés après activation parthénogénétique, aboutit toujours à une segmentation abortive, quel que soit le mode d'évolution du spermatozoïde fécondant. Lorsque le pronucléus mâle essaie de se mêler au pronucléus femelle, il apparaît des anomalies dès la première division : formation de nombreux subnucléi, de blastomères surnuméraires avec ou sans noyau. Lorsque le spermatozoïde n'évolue pas, par suite d'une pénétration plus tardive, la première segmentation peut être normale mais les divisions suivantes sont perturbées par la présence de la chromatine mâle.

7 p. Ioo seulement des œufs activés et fécondés sont polyspermiques, ce qui démontre l'existence d'une véritable réaction d'activation au moment de la pénétration du spermatozoïde fécondant dans presque tous les œufs parthénogénétiques.

En règle générale, chez les animaux la pénétration du spermatozoïde fécondant, déclenche une réaction de défense de l'œuf à l'égard des spermatozoïdes, de telle sorte que la fécondation demeure monospermique. 
Cette règle s'applique aux Mammifères chez lesquels la polyspermie ne se produit naturellement que dans un très faible pourcentage des œufs : I,4 p. Ioo chez la Lapine, I, 2 p. Ioo chez la Ratte (AUSTin et BRAdEN, I953), I,2 p. Ioo chez la Souris (BRAdEN, Austin et David, r954).

Mais la fréquence d'œufs polyspermiques est augmentée dans certaines conditions : L orsque l'œuf est âgé, le pourcentage d'œufs polyspermiques augmente. Par accouplement retardé chez la Ratte (accouplement en fin d'œstrus), le nombre d'œufs polyspermiques obtenus est de 9,2 p. Ioo (AUSTIN et BRADEN, I953). D'autres facteurs peuvent avoir également une action : 1'hyperthermie générale, l'âge de la femelle, la souche (voir la mise au point récente de PIKo, I96I).

Lorsqu'il y a dispermie, ou même trispermie, la pénétration des spermatozoïdes est presque simultanée. Leur évolution dans le cytoplasme de l'œuf est parallèle. Il n'a pas été observé de façon certaine de cas de "refécondation " d'œufs, c'est-à-dire de pénétration d'un deuxième spermatozoïde à un stade avancé du développement.

La polyspermie est limitée par deux facteurs :

I) La quantité de spermatozoïdes présents dans les trompes au moment de la fécondation est faible (quelques centaines chez la Lapine, Chang, I953 ; Austrin et Bishop, I957). La fréquence de collision ovocyte-spermatozoïde a été étudiée par BRADEN et AUSTIN, I954: elle est telle qu'elle offre de bonnes chances de fécondation mais ne permet pas un nombre excessif de rencontre.

2) Le deuxième facteur réglant la polyspermie est la " réaction propre " de l'œuf. Cette réaction se situe à deux niveaux; dans la zone pellucide et dans la membrane vitelline. Dès qu'un spermatozoïde pénètre dans la membrane pellucide il se produit une réaction qui tend à empêcher la pénétration d'un second spermatozoïde. Cette réaction est rapide chez certaines espèces (Chien, Brebis...,) mais elle est très lente pour l'ouf de Lapine. Aussi de nombreux spermatozoïdes pénètrent-ils dans l'espace périvitellin. Dans ce cas la monospermie est assurée au niveau de la membrane vitelline, prévenant la pénétration dans le cytoplasme de spermatozoïdes surnuméraires.

Les travaux de BATAILION (IgI2) ont bien montré que chez les Amphibiens, 1'activation parthénogénétique conduit à l'émission du deuxième globule polaire, et à une réaction corticale, qui rapelle en tout point celle de la fécondation puisque l'œuf ainsi activé devient infécondable.

Mais Thibaurt (r949) a observé que si l'œuf de Ratte activé parthénogénétiquement par le froid réagissait toujours par l'émission du deuxième globule polaire, quelles que soient l'intensité et la durée du traitement activant, une certaine proportion d'ovocytes de Lapine soumis à un refroidissement de très courte durée, vers $0^{\circ} \mathrm{C}$ était susceptible de se développer sans manifester l'un des signes caractéristiques de l'activation ; 1'émission du deuxième globule polaire. CHANG (I954) a précisé qu'il était possible d'obtenir très régulièrement le développement d'ovocytes de Lapines par un refroidissement plus ménagé, ro ${ }^{\circ} \mathrm{C}$, et plus long. 24 heures.

A partir du moment où l'ovocyte reconstitue un pronucleus et se segmente, on doit nécessairement admettre qu'il a été activé par le traitement parthénogénétique, mais on pouvait se demander si dans le cas de la Lapine où l'émission du deuxième globule polaire ne se produit pas, l'activation était complète, et notamment si la " réaction propre ", telle que l'a décrite BATAILLON, et les phénomènes qui 1'accompagnent ou la suivent, avaient lieu dans de tels œufs.

Il semblait que non puisque CHANG (r952) avait signalé l'obtention de féconda- 
tions d'ovocytes de Lapine activés par conservation à Io ${ }^{\circ} \mathrm{C}$ pendant 24 heures. Dans ces conditions, 57 p. I00 des I05 oufs examinés étaient activés. Sur 4 I cufs ainsi activés et transférés dans les trompes d'une Lapine préalablement accouplée à un mâle fécond, 32 étaient normalement fécondés ( 78 p. Ioo); 4 présentaient des noyaux anormaux et 5 n'étaient pas fécondés.

Cependant, Austrn (I954) devait confirmer, chez le Rat, que I7 p. Ioo des ovocytes activés par le froid à $0^{\circ} \mathrm{C}$ et présentant des signes complets d'activation : émission du deuxième globule polaire, rétraction du cytoplasme dans la membrane pellucide, pouvaient encore être fécondés. Sur I30 œufs, 23 présentaient un pronuclétus mâle normal, mais I7 seulement avaient des pronuclei mâle et femelle normaux.

Ainsi même pour des ovocytes présentant des signes d'activation rappelant en tous points ceux qui accompagnent la fécondation, tant par l'émission du deuxième globule polaire, que par la rétraction de l'œuf à l'intérieur de la membrane pellucide la fécondation semble possible après activation parthénogénétique, c'est dire que l'activation parthénogénétique diffère de l'activation spermatique.

Nous avons donc repris l'étude de cette question sur l'ovocyte de Lapine, les techniques de fécondation in vitro, récemment mises au point par DAUZIER et THIBAULT (I954-r96I) permettant une étude plus précise des différents facteurs auxquels est soumis l'ovocyte : la température de refroidissement et sa durée, les délais de mise en contact du sperme après réchauffement.

\section{MATÉRIEL E'T MÉTHODES}

Nous avons utilisé dans cette expérience 430 Lapines provenant d'élevage, non sélectionnées et gardées deux mois avant utilisation dans des conditions standards (nourriture et isolement individuel des animaux).

Les femelles destinées à la récolte des spermatozoïdes étaient accouplées, I 2 heures avant l'abattage, à des mâles féconds. Après abattage les spermatozoïdes étaient obtenus par perfusion des cornes utérines avec $0,2 \mathrm{ml}$ de solution de Locke à $37,5^{\circ} \mathrm{C}$. On sait que les oufs chez la Lapine, séjournent trois jours dans les trompes, il est donc possible de recueillir les spermatozoïdes dans les cornes, sans risque d'entraîner des oufs fécondés. Le contrôle des spermatozoïdes dans le perfusat était effectué aussitôt entre lame et lamelle au microscope à contraste de phase, et leur nombre évalué de + $\grave{a}++++$.

Les femelles destinées à produire des ovocytes vierges étaient accouplées i 2 heures avant l'abattage à des mâles vasectomisés. Les ovocytes étaient recueillis dans un verre de montre par perfusion des trompes avec une solution de Locke et transportés à l'aide de micropipettes et sous la loupe binoculaire, dans des tubes de culture où ils étaient mis en suspension dans différents milieux, suivant la technique décrite par Thibault et Dauzier (I96I).

Les milieux suivants ont été utilisés :

- Liquide de Locke.

- Milieu de Hammond. C'est une solution saline équilibrée contenant en outre du jaune et du blanc d'œuf. Le pH de la solution est compris entre 7,5 et 7,8 . Cette solution avait été utilisée avec succès pour la culture des ceufs de Souris (HAmmond, I949).

- Dilueur au lait utilisé généralement pour la conservation du sperme de Taureau (ALMQUIST, Flipse et Thacker, r954). Ce dilueur se compose essentiellement de lait en poudre dilué à raison de Io p. roo dans de l'eau.

- Sérum homologue ou mélange à parties égales de Locke et de sérum.

En prenant comme critère la qualité apparente du cytoplasme et du noyau, les meilleurs résultats ont été obtenus en utilisant comme milieu le sérum homologue (Tableau I). C'est à cette conclusion qu'arrivent la plupart des auteurs pour les cufs fécondés de Lapine (Purshottam et Pincus, I96I). 
TABLEAU I

Etude de différents milieux de culture

Refroidissement $\dot{a} 10^{\circ} \mathrm{C}$ pendant $24 \mathrm{~h}$ et culture $\grave{a} 37^{\circ} \mathrm{C}$ pendant $8 \mathrm{~h}$

\begin{tabular}{|c|c|c|c|c|c|c|}
\hline Lapine & $\begin{array}{l}\text { Milieu de } \\
\text { culture }\end{array}$ & $\begin{array}{l}\text { Nombre } \\
\text { d'ovules }\end{array}$ & $\begin{array}{c}\text { Euf avec } 1 \\
\text { ou plusieurs } \\
\text { pronucléi }\end{array}$ & $\begin{array}{l}\text { Euf non } \\
\text { activé }\end{array}$ & $\begin{array}{l}\text { Étude du } \\
\text { cytoplasme } \\
\text { apprécié de } \\
+ \text { à }+++\end{array}$ & $\begin{array}{l}\text { État du } \\
\text { noyau }\end{array}$ \\
\hline \multirow[t]{2}{*}{$\begin{array}{l}\mathrm{GE} \\
\mathrm{GF} \\
\mathrm{GG}\end{array}$} & $\begin{array}{c}\text { Serum } \\
\text { homologue }\end{array}$ & $\begin{array}{l}12 \\
10 \\
10\end{array}$ & $\begin{array}{l}11 \\
10 \\
10\end{array}$ & $\begin{array}{l}1 \\
0 \\
0\end{array}$ & \multirow[t]{2}{*}{+++} & \multirow[t]{2}{*}{$\begin{array}{c}\text { normal } \\
1 \text { seul } \\
\text { pronucléus }\end{array}$} \\
\hline & & 32 & $31 \mid 97 \%$ & $1 \mid 3 \%$ & & \\
\hline \multirow[t]{2}{*}{$\begin{array}{l}\text { FT } \\
\text { FU } \\
\text { FV } \\
\text { FW }\end{array}$} & Locke & $\begin{array}{l}7 \\
7 \\
8 \\
9\end{array}$ & $\begin{array}{l}7 \\
7 \\
5 \\
2\end{array}$ & $\begin{array}{l}0 \\
0 \\
3 \\
7\end{array}$ & + & $\begin{array}{l}\text { normal } \\
1 \text { seul } \\
\text { pronucléus }\end{array}$ \\
\hline & & 31 & $21 \mid 68 \%$ & $10 \mid 32 \%$ & & \\
\hline \multirow[t]{2}{*}{$\begin{array}{l}\text { GH } \\
\text { GI } \\
\text { GJ } \\
\text { GK }\end{array}$} & \multirow[t]{2}{*}{$\begin{array}{l}\text { Milieu } \\
\text { de } \\
\text { Hammond }\end{array}$} & $\begin{array}{l}4 \\
6 \\
6 \\
7\end{array}$ & $\begin{array}{l}4 \\
6 \\
5 \\
3\end{array}$ & $\begin{array}{l}0 \\
0 \\
1 \\
4\end{array}$ & \multirow[t]{2}{*}{$+t$} & \multirow[t]{2}{*}{$\begin{array}{l}\text { normal } \\
1 \text { seul } \\
\text { pronucléus }\end{array}$} \\
\hline & & 23 & $18 \quad 78 \%$ & $5 \mid 22 \%$ & & \\
\hline \multirow[t]{2}{*}{$\begin{array}{l}\mathrm{FX} \\
\mathrm{FZ} \\
\mathrm{GA}\end{array}$} & \multirow[t]{2}{*}{$\begin{array}{l}\text { Dilueur } \\
\text { au lait }\end{array}$} & $\begin{array}{r}6 \\
7 \\
10\end{array}$ & $\begin{array}{l}3 \\
6 \\
8\end{array}$ & $\begin{array}{l}3 \\
1 \\
2\end{array}$ & \multirow[t]{2}{*}{++} & \multirow[t]{2}{*}{$\begin{array}{c}\text { anormal } \\
\text { nombreux } \\
\text { subnucléi }\end{array}$} \\
\hline & & 23 & \begin{tabular}{l|l|l}
17 & 71
\end{tabular} & \begin{tabular}{l|l}
6 & $26 \%$
\end{tabular} & & \\
\hline
\end{tabular}

Deux types de refroidissement ont été employés : le refroidissement à une température de ${ }^{\circ}{ }^{\circ} \mathrm{C}$ pendant 24 heures, les ovocytes étant placés dans de petits tubes de verre. Mais un refroidissement de 24 heures entraîne un vieillissement de l'œuf, et l'on sait (PIKo, I96r) qu'un œuf âgé est aisément polyspermique, ce qui signifie que même après la fécondation, la réaction de l'œuf reste faible.

Aussi avons-nous cherché à déclencher l'activation par un refroidissement brutal et bref. Les ovocytes sont déposés sur une lamelle, dans une goutte de milieu de culture, et la lamelle est posée sur un bloc de glace fondante pour une durée variant de 3 o secondes à 3 minutes. Aussitôt après les ovocytes sont replacés dans les tubes de culture à $37,5^{\circ} \mathrm{C}$. Malheureusement comme nous allons le voir l'activation dans de telles conditions se produit trop irrégulièrement pour qu'il ait été possible d'utiliser ces œufs pour des essais de fécondation.

Les ovocytes activés par refroidissement pendant 24 heures sont inséminés immédiatement après réchauffement avec des spermatozoïdes maturés obtenus par perfusion des cornes utérines. Les ovocytes et le perfusat contenant les spermatozoïdes sont déposés dans des tubes de culture, ceux-ci étant placés dans un dispositif à rotation discontinue (Thibault et Dauzier, I96r).

Dans une autre série d'expériences, les ovocytes activés ont été transférés dans les trompes de Lapines accouplées à un mâle normal I 5 à I 6 heures avant l'opération (d'après BRADEN, I953, le nombre de spermatozoïdes présents dans les trompes est maximum i6 heures après l'accouplement). l'éther.

Les lapines ont été laparotomisées sous anesthésie intraveineuse au Nembutal, puis gazeuse à

Les ovocytes ont été introduits dans les trompes jusqu'à l'isthme par le pavillon, à l'aide d'une micropipette et ont été récupérés quelques heures après par perfusion des trompes avec du Locke.

Après des temps de culture in vitro allant de 1 à $4^{8}$ heures ou après séjour de 6 heures dans les trompes d'une Lapine hôte tous les œufs ont été fixés au Bouin Hollande, inclus par la méthode de double inclusion gélose-paraffine, coupés à to $\mu$, colorés à l'hématoxyline de Regaud et étudiés au microscope. 
TABLEAU 2

Refroidissement $\dot{a} \mathrm{o}^{\circ} \mathrm{C}$ et culture pendant 8 heures

\begin{tabular}{|c|c|c|c|c|c|c|c|c|c|c|}
\hline \multirow[t]{2}{*}{ Lapine } & \multirow[t]{2}{*}{$\begin{array}{l}\text { Nombre } \\
\text { d'ovules }\end{array}$} & \multirow{2}{*}{$\begin{array}{l}\text { Durée de } \\
\text { refroidis- } \\
\text { sement }\end{array}$} & \multicolumn{2}{|c|}{$\begin{array}{l}\text { Eufs non } \\
\text { activés }\end{array}$} & \multicolumn{2}{|c|}{$\begin{array}{l}\text { OEufs activés } \\
\text { mais n'ayant pas } \\
\text { reconstitué de } \\
\text { pronucléus }\end{array}$} & \multicolumn{2}{|c|}{$\begin{array}{c}\text { (Eufs } \\
\text { avec pronucléus }\end{array}$} & \multicolumn{2}{|c|}{$\begin{array}{l}\text { Émission } \\
\text { du } 2^{\text {e }} \mathrm{CP} \text {. }\end{array}$} \\
\hline & & & Nombre & $\%$ & Nombre & $\%$ & Nombre & $\%$ & Nombre & $\%$ \\
\hline CS $\ldots \ldots$ & 10 & $30 \mathrm{~s}$ & 10 & 100 & & & & & & \\
\hline CT ..... & 9 & - & 9 & 100 & & & & & & \\
\hline $\mathrm{CU} \ldots$ & 5 & - & 5 & 100 & & & & & & \\
\hline CV...... & 7 & - & 2 & 28,5 & 3 & 42,8 & 2 & 28,5 & & \\
\hline $\mathrm{CW} \ldots$. & 11 & - & 2 & 18,2 & 2 & 18,2 & 7 & 63,6 & 2 & 18,2 \\
\hline $\mathrm{CX} \ldots \ldots$ & 5 & $\rightarrow$ & 2 & 40 & 3 & 60 & & & & \\
\hline $\mathrm{DA} \ldots \ldots$ & 11 & - & 6 & 54,6 & 5 & 45,4 & & & 2 & 18,2 \\
\hline \multirow{2}{*}{ DB ..... } & 7 & 一 & 7 & 100 & & & & & & \\
\hline & 65 & & 43 & 66 & 13 & 20 & 9 & 14 & 4 & 6 \\
\hline$\overline{C L} \ldots$ & 10 & $40 \mathrm{~s}$ & 8 & 804 & 2 & 20 & & & & \\
\hline $\mathrm{CM} \ldots$. & 7 & $\cdots$ & 5 & 71,4 & 1 & 14,5 & 1 & 14,5 & 1 & 14,5 \\
\hline $\mathrm{CN} \ldots$. & 8 & - & 5 & 62,5 & 3 & 37,5 & & & & \\
\hline CO...... & 6 & - & 3 & 50 & 3 & 50 & & & & \\
\hline $\mathrm{CP} \ldots$ & 1 & -- & 1 & 100 & & & & & & \\
\hline $\mathrm{CQ} \ldots .$. & 8 & - & 8 & 100 & & & & & & \\
\hline $\mathrm{CR} \ldots$. & 4 & - & & & 4 & 100 & & & & \\
\hline \multirow{2}{*}{ DD $\ldots}$. & 1 & - & 1 & 100 & & & & & & \\
\hline & 45 & & 31 & 69 & 13 & 29 & 1 & 2 & 1 & 2 \\
\hline $\mathrm{BY} \ldots \ldots$ & 5 & $60 \mathrm{~s}$ & 2 & 40 & 1 & 20 & 2 & 40 & 1 & $\overline{20}$ \\
\hline$B Z \ldots \ldots$ & 5 & - & & & 3 & 60 & 2 & 40 & 5 & 100 \\
\hline CA..... & 5 & - & & & & & 5 & 100 & 5 & 100 \\
\hline $\mathrm{CB} \ldots$ & 9 & - & 3 & 33,3 & & & 6 & 66,7 & 6 & 66,7 \\
\hline $\mathrm{CC} \ldots$ & 11 & - & 2 & 18,2 & & & 9 & 81,8 & 9 & 81,8 \\
\hline $\mathrm{CD} \ldots \ldots$ & 9 & - & 1 & 11,1 & & & 8 & 88,9 & 8 & 88,9 \\
\hline CY .... & 4 & - & & & & & 4 & 100 & 4 & 100 \\
\hline $\mathrm{CZ}$ & 3 & - & 1 & 33,3 & 2 & 66,6 & & & & \\
\hline $\mathrm{EH} \ldots \ldots$ & 5 & - & 2 & 40 & 3 & 60 & & & & \\
\hline $\mathrm{EI} \ldots \ldots$ & 5 & - & & & 5 & 100 & & & & \\
\hline \multirow[t]{2}{*}{ EJ $\ldots}$. & 5 & - & & & 5 & 100 & & & & \\
\hline & 66 & & 11 & 16,7 & 19 & 28,8 & 36 & 54,5 & 38 & 57,6 \\
\hline$\overline{\mathrm{DS}} \ldots \ldots$ & 3 & $80 \mathrm{~s}$ & 3 & 100 & & & & & & \\
\hline DT $\ldots .$. & 9 & 一 & 8 & 88,9 & & & 1 & 11,1 & 1 & 11,1 \\
\hline DU $\ldots \ldots$ & 10 & - & 8 & 80 & 2 & 20 & & & & \\
\hline $\mathrm{DV} \ldots \ldots$ & 6 & - & 5 & 83,3 & 1 & 16,7 & & & & \\
\hline $\mathrm{DX} \ldots$ & 2 & - & 1 & 50 & 1 & 50 & & & & \\
\hline DY .... & 7 & - & 6 & 85,7 & & & 1 & 14,5 & 1 & 11,5 \\
\hline EK ..... & 9 & - & 7 & 77,8 & 2 & 22,2 & & & & \\
\hline EN $\ldots$. & 6 & - & 6 & 100 & & & & & & \\
\hline \multirow[t]{2}{*}{$\mathrm{EO} \ldots$} & 5 & - & 4 & 80 & & & & & & \\
\hline & 57 & & 47 & 82,45 & 6 & 10,5 & 2 & 3,50 & 2 & 3,50 \\
\hline$\overline{C G} \ldots \ldots$ & 10 & $180 \mathrm{~s}$ & 2 & 20 & 5 & 50 & 1 & 10 & 2 & 20 \\
\hline $\mathrm{CH} \ldots$. & 11 & - & 4 & 36,4 & 6 & 54,5 & 1 & 9,1 & 3 & 27,3 \\
\hline CI ..... & 9 & - & 2 & 22,2 & 3 & 33,3 & 4 & 44,4 & & \\
\hline $\mathrm{CJ} \ldots$. & 9 & - & 7 & 77,8 & 2 & 22,2 & & & & \\
\hline $\mathrm{CK} \ldots$. & 3 & - & 3 & 100 & & & & & & \\
\hline DE $\ldots$. & 5 & 一 & 1 & 20 & 1 & 20 & 3 & 60 & 3 & 60 \\
\hline \multirow[t]{2}{*}{ DF $\ldots}$. & 4 & - & & & 2 & 50 & 2 & 50 & & \\
\hline & 51 & & 19 & 37,25 & 19 & 37,25 & 11 & 21,5 & 8 & 15,7 \\
\hline
\end{tabular}




\section{RÉSULTATS}

\section{A. - Confirmation de l'activation PaRthénogénétioue APRÈS REFROIDISSEMENT}

\section{I0 Ovocytes activés à $0^{\circ} \mathrm{C}$ de 30 à $\mathrm{I} 80$ secondes}

a) Sur 66 ovocytes ainsi refroidis à $0^{\circ} \mathrm{C}$ pendant 60 secondes puis remis en culture pendant 8 heures, II ovocytes conservent à peu près totalement leur fuseau et n'ont donc pas été activés, soit $\mathrm{I} 7 \mathrm{p}$. Ioo. Les autres ovocytes présentent des signes divers d'activation : un ovocyte a reconstitué un noyau diploïde. 38 émettent leur deuxième globule polaire, soit $5^{8} \mathrm{p}$. Ioo et $3^{6}$ reconstituent un noyau haplö̈de. Les 2 autres ne reconstituent pas de noyau.

b) Pour une durée de refroidissement de 30 et 40 secondes, le pourcentage d'ovocytes non activés est beaucoup plus élevé : 66 p. Ioo à 69 p. Ioo.

Les taux correspondants d'émission du deuxième globule polaire sont de $6 \mathrm{p}$. Ioo et $2 \mathrm{p}$. Ioo, et il y a peu de reconstitution de noyau. Cette durée de refroidissement est donc manifestement insuffisante.

c) Après un refroidissement de $r 80$ secondes le pourcentage d'ovocytes activés augmente (59 p. IOo) ; mais il n'y a pas régulièrement formation de pronucléus : 2 I p. IOO.

Le temps de refroidissement de 60 secondes à $0^{\circ} \mathrm{C}$ donne donc la proportion la plus élevée d'ovocytes présentant l'activation la plus complète avec émission du deuxième globule polaire et la restauration d'un pronucléus haploïde.

Ces résultats confirment et précisent ceux que Thibauli (r949) avait rapportés, mais nous constatons combien est variable même pour un temps de refroidissement identique, la réaction des ovocytes.

\section{$2^{\circ}$ Ovocytes activés par refroidissement à $\mathrm{ro}^{\circ} \mathrm{C}$ pendant 24 heures}

Des essais ont été effectués à des températures variant de 5 à $I^{\circ}{ }^{\circ} \mathrm{C}$ mais, c'est à cette dernière température que nous avons obtenu les meilleurs résultats.

Sur Io7 ovocytes ainsi refroidis nous avons obtenu un pourcentage d'activation de roo p. xoo.

Les cufs fixés immédiatement après le séjour à $10^{\circ} \mathrm{C}$ montrent dans tous les cas la rotation de $90^{\circ}$ de la plaque équatoriale, étape préparatoire à l'émission du deuxième globule polaire, mais en même temps la disparition complète du deuxième fuseau de maturation de telle sorte que la mitose ne peut pas s'achever et le deuxième globule polaire se former.

Après une durée de culture de 30 minutes, on constate que les chromosomes migrent vers le centre de 1'œuf. Au bout d'une heure ils commencent à former un noyau; celui-ci est achevé après 2 à 3 heures. Les images observées sont identiques à celles que Thibaurit a décrites (r949). 

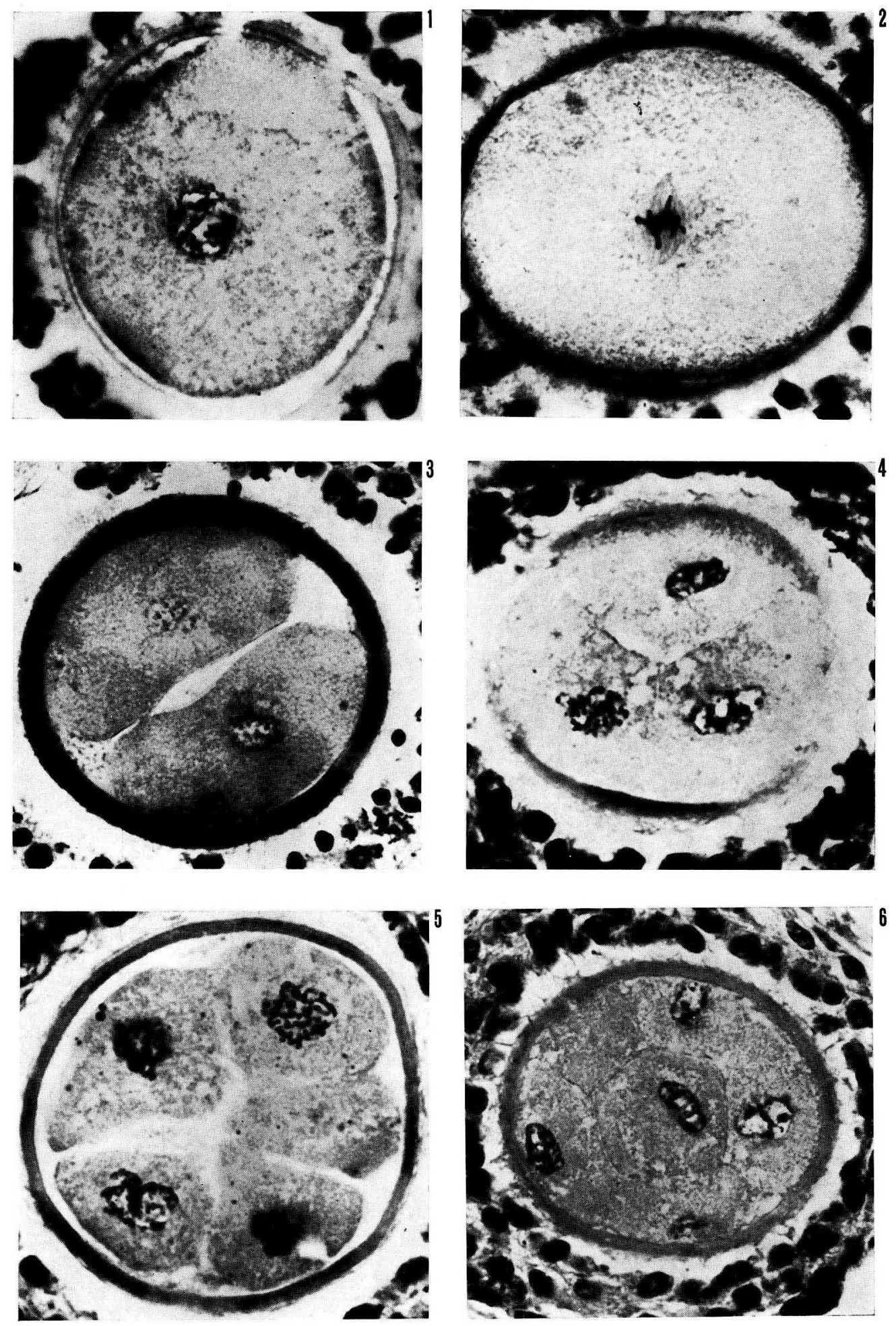

PLANCHE I. - Ovocyles activés par un refroidissement d $10^{\circ} \mathrm{C}$ pendant 24 heures et cultivés dans du Locke-Serum homologue

I. $-6 \mathrm{~h}$ de culture - formation d'un pronucléus diploïde, le deuxième globule polaire n'est pas émis. 2. - Ier fuseau de segmentation après 10 $\mathrm{h}$ de culture. 3. - Stade 2 blastomères après $\mathrm{I} 2 \mathrm{~h}$ de culture. 4. - Stade 4 blastomères après $24 \mathrm{~h}$ de culture. $5 .-$ Stade 8 blastomères après $32 \mathrm{~h}$ de culture. 6. - Stade I 2 blastomères après $48 \mathrm{~h}$ de culture. 


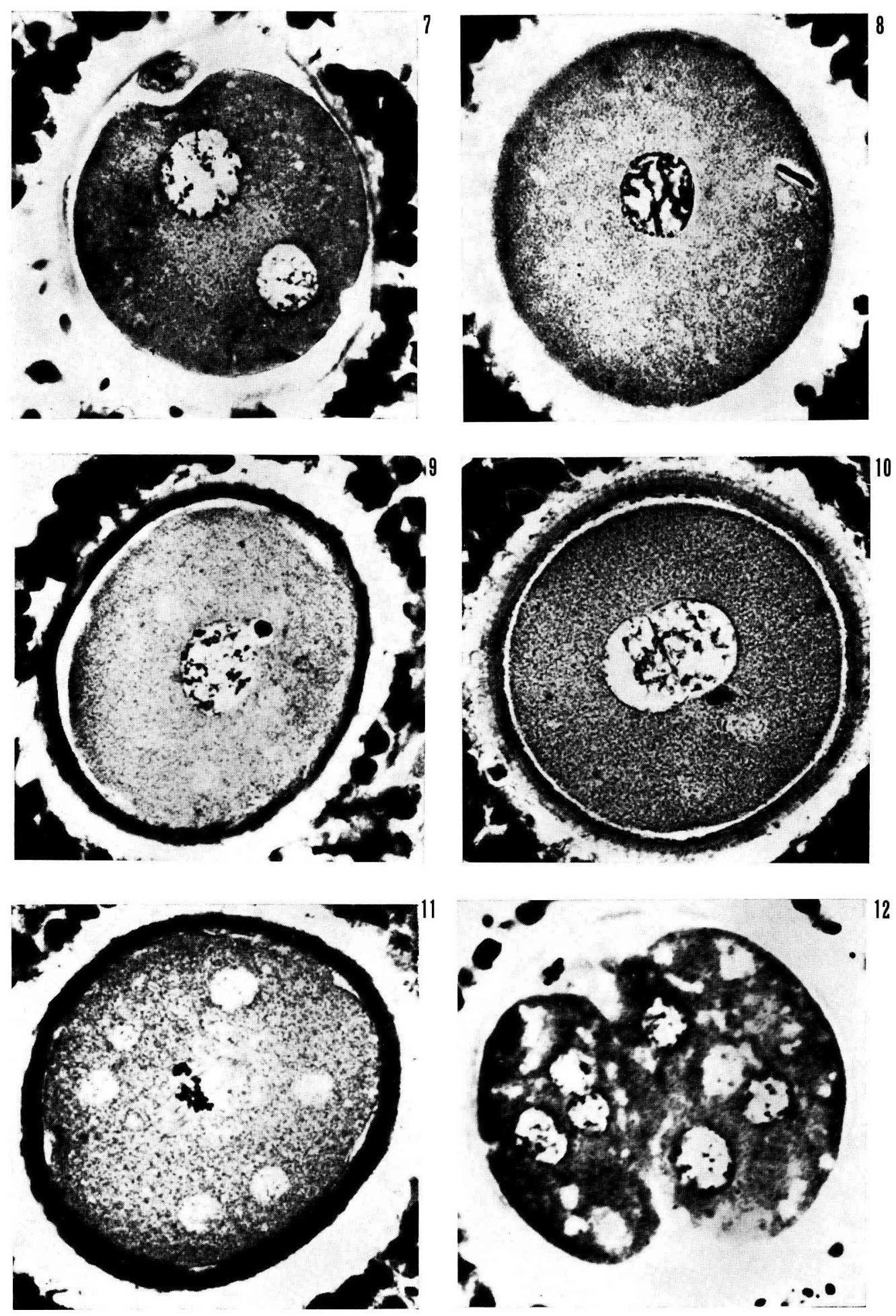

Planche II. - Ovocytes activés par refroidissement el inséminés

7. - Le pronucleus mâle a un aspect normal mais sa taille est inférieure à celle du pronucléus femelle.

8. - Évolution anormale du spermatozö̀de fécondant $3 \mathrm{~h}$ 40 après l'insémination.

g. - Aspect ponctiforme du pronucleus mâle.

Io. - Pronucleus mâle ponctiforme - 2 pronuclei sont femelles.

I I. - Segmentation de l'œuf.

Ia chromatine mâle reste à côté du fuseau ct ne participe pas à la division.

12. - Segmentation abortive - cytolyse de l'auf $\rightarrow$ présence de plusieurs noyaux dans chaque blastomère. 
. 
$\mathrm{L}$ a première division de segmentation a lieu $\mathrm{I} 2$ heures après le refroidissement. Dans le cas d'une fécondation normale, elle se produit io heures après la ponte ovulaire. Il y a donc un léger retard dans le développement de l'ovocyte activé parthénogénétiquement. Compte tenu du but du travail, le temps de culture in vitro n'a pas été poussé au-delà de 48 heures. Tous les œufs observés étaient segmentés en I2 à $I 6$ blastomères.

Lorsque les ovocytes sont mis en culture dans du dilueur au lait, les chromosomes ne reconstituent pas un pronucléus central, mais des subnucléi. Il en est parfois de même dans le liquide de Locke.

La régularité de l'évolution de tous les oufs ainsi refroidis à $10^{\circ} \mathrm{C}$ pendant 24 heures et remis en culture nous a conduit à utiliser cette technique en vue de l'étude de la fécondabilité des ovules parthénogénétiques, puisque dans ce cas, aucune erreur n'est possible : toute fécondation observée s'est nécessairement produite dans un œuf activé.

\section{B. - FÉcondation aprìs activation par ReFroidissement a Io C PENDANT 24 HEURES}

Les ovules ainsi activés sont mis en présence de sperme maturé, puis fixés à des temps suffisamment courts pour pouvoir distinguer le procucléus mâle du pronucléus femelle. Sur 247 ovocytes inséminés, $7 \mathrm{I}$ sont sûrement fécondés soit $29 \mathrm{p}$. IoO.

Dans les expériences de fécondation in vitro d'ovules normaux, les spermatozoïdes pénètrent 2 heures 30 à 3 heures après la mise en contact des ovules et du sperme. Trois œufs ont été trouvés fécondés après I heure 50 de culture en présence de spermatozoïdes et les autres après 3 heures ou plus. On observe de nombreux spermatozoïdes sous la membrane pellucide de certains oufs, mais ceci est fréquent dans le cas de fécondation normale.

Le spermatozoïde qui pénètre dans le cytoplasme peut avoir une évolution très variable (Tableat 3).

En considérant uniquement les œufs cultivés pendant 6 à 8 heures on peut observer les cas suivants :

- le spermatozoïde peut constituer un pronucléus ayant une structure normale et migrant vers le noyau femelle, mais sa taille reste inférieure à celle du noyau femelle ce qui est contraire à ce qui existe normalement chez la Lapine ('THibauL'T, I962). On peut voir parfois se développer un aster. Dans ces cas, dans le noyau femelle, la chromatine s'oriente vers le noyau mâle comme elle le fait normalement ('THIBAULT et DAUZIFR, I96r).

Sur les 7 r œeufs fécondés après activation, 5 ont plusieurs pronucléi mâles normaux dans leur cytoplasme ; 5 pronucléi mâles ont été comptés dans un seul œuf. Le pourcentage de polyspermie est de $7 \mathrm{p}$. Ioo. Ce qui signifie que la fréquence de polyspermie dans ces œufs parthénogénétiques fécondés est plus élevée que dans les conditions naturelles ( $I, 4 \mathrm{p}$. Ioo chez la Lapine) mais proche de ce que l'on observe dans les œufs âgés, chez cette espèce, ce qui est le cas.

- le spermatozoïde peut aussi avoir une évolution très anormale. La tête du spermatozoïde, après avoir légèrement gonflé, donne naissance à un pronucléus ponctiforme. Il peut s'accoler au noyau femelle en gardant cette structure, mais on peut le trouver également dans différentes positions, jusqu'à la zone externe de l'œuf.

Annales de Biologie animale. - Ig62. 
Fécondation in vitro après refroidi

\begin{tabular}{|c|c|c|c|c|c|}
\hline Lapine & Nombre d'ovules & $\begin{array}{c}\text { Quantité de spz. } \\
\text { pour l'insémination } \\
\text { appréciée de } \\
+\grave{a}++++\end{array}$ & $\begin{array}{l}\text { Temps de } \\
\text { culture en } \mathrm{h}\end{array}$ & $\begin{array}{c}\text { Eufs non fécondés } \\
\text { mais avec pronu- } \\
\text { cléus } \$\end{array}$ & $\begin{array}{l}\text { Eufs en dégénéres- } \\
\text { cence ou anormaux }\end{array}$ \\
\hline 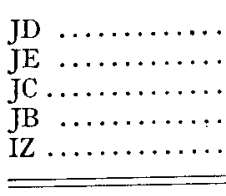 & $\begin{array}{r}2 \\
8 \\
7 \\
8 \\
10\end{array}$ & $\begin{array}{r}+++ \\
+++ \\
++ \\
++++ \\
+\end{array}$ & $\begin{array}{l}1 \\
1 \\
1,02 \\
1,50 \\
2,00\end{array}$ & $\begin{array}{l}2 \\
8 \\
7 \\
5 \\
9\end{array}$ & 1 \\
\hline $\begin{array}{l}\text { IL }{ }^{1}{ }^{\text {IK }} \\
\text { IJ } \\
\text { IJ }\end{array}$ & $\begin{array}{r}8 \\
9 \\
3 \\
4 \\
6 \\
3 \\
14 \\
8 \\
12 \\
1 \\
8 \\
5 \\
9 \\
2 \\
12 \\
4 \\
4 \\
7 \\
7 \\
10 \\
10 \\
4 \\
9 \\
2 \\
11 \\
5 \\
8 \\
9 \\
5 \\
5 \\
6 \\
3 \\
6 \\
4 \\
2 \\
5 \\
8 \\
5 \\
4\end{array}$ & $\begin{array}{r}++ \\
+ \\
++ \\
++++ \\
+++ \\
+ \\
++ \\
+++ \\
++ \\
+ \\
+ \\
++ \\
++++ \\
+++ \\
++++ \\
++++ \\
+ \\
++ \\
+++ \\
++++ \\
+++ \\
+++ \\
++++ \\
+ \\
+ \\
++++ \\
++++ \\
++++ \\
++ \\
+++ \\
+ \\
+ \\
+++ \\
++ \\
+++ \\
+++ \\
+++ \\
+++\end{array}$ & $\begin{array}{r}3,31 \\
3,36 \\
3,40 \\
3,28 \\
5,00 \\
5 \\
5 \\
6,34 \\
6,40 \\
6,47 \\
7,05 \\
7,32 \\
7,38 \\
7,40 \\
6,45 \\
6,34 \\
6,06 \\
7,15 \\
10,07 \\
10,04 \\
9,57 \\
10,00 \\
10,15 \\
10,19 \\
11,30 \\
11,30 \\
11,30 \\
11,01 \\
10,59 \\
11,00 \\
11,44 \\
11,43 \\
11,42 \\
24,31 \\
24,31 \\
24,17 \\
23,53 \\
23,42 \\
23,42\end{array}$ & $\begin{array}{r}3 \\
5 \\
1 \\
5 \\
2 \\
2 \\
1 \\
1 \\
\\
2 \\
3 \\
3 \\
6 \\
7 \\
2 \\
8 \\
1 \\
10 \\
1 \\
3 \\
8 \\
3 \\
5 \\
5 \\
3 \\
6 \\
4\end{array}$ & $\begin{array}{l}1 \\
3 \\
5 \\
3 \\
3 \\
5 \\
8 \\
\\
2\end{array}$ \\
\hline & 247 & & & $11^{\prime} t$ & 62 \\
\hline
\end{tabular}


Le pourcentage d'œufs fécondés (29 p. IOo) obtenus après activation est plus faible que celui obtenu dans les mêmes conditions avec des ovocytes vierges (65 p. Ioo Thibaulit et DAUzIER, I96r). On pouvait penser que les conditions de fécondation in vitro étaient moins bonnes que les conditions normales, aussi avons-nous tenté d'améliorer le pourcentage d'œufs fécondés, en les transplantant après refroidissement dans les trompes d'une Lapine hôte préalablement accouplée I6 heures avant à un mâle normal. En effet, les meilleurs résultats obtenus par THIBAULT et DaUZIER (I96I) restent inférieurs aux résultats de fécondation in vivo ( $76 \mathrm{p}$. Ioo contre $95 \mathrm{p}$. Ioo chez les témoins).

Les Lapines ont été abattues 6 heures après le transfert des oufs, soit 22 heures après l'accouplement, et les aufs récupérés ont été étudiés histologiquement. Les œufs de la Lapine hôte sont fécondés mais ils sont soit en division desegmentation, soit au stade 2 blastomères. Il n'est donc pas possible de les confondre avec les œufs transférés qui n'ont que 6 heures de développement et qui ne se diviseront que 6 heures plus tard comme nous l'avons rappelé précédemment.

D'autre part, le nombre d'œufs de la Lapine hôte est connu avec précision au moment de la laparotomie, d'après le nombre de points d'ovulation.

Sur 49 ovocytes activés par le froid, puis transférés dans 4 Lapines, 22 ont été fécondés, mais seulement 6 ont un pronucléus mâle ayant une structure normale femelle (I2 p. Ioo). Dans I6 œufs (33 p. roo) la chromatine mâle est contre le noyau et $\mathrm{a}$, soit un aspect très compact avec une limite bien nette, soit un aspect plus diffus.

Le pourcentage d'œufs fécondés s'élève donc à 45 p. Ioo, c'est dire que dans des conditions normales de la fécondation, près de la moitié des ovules parthénogénétiques sont fécondables (tableau 4).

TABLEAU 4

Fécondation in vivo après transfert d'ovocytes activés in vitro

\begin{tabular}{|c|c|c|c|c|c|c|}
\hline \multirow[b]{2}{*}{ Lapine } & \multirow[b]{2}{*}{$\begin{array}{c}\text { Nombre } \\
\text { d'ovules } \\
\text { transplantés }\end{array}$} & \multirow[b]{2}{*}{$\begin{array}{c}\text { Eufs non } \\
\text { fécondés mais } \\
\text { avec pronucléus }\end{array}$} & \multicolumn{2}{|c|}{ (Eufs fécondés } & \multirow[b]{2}{*}{$\begin{array}{l}\text { Nombre total } \\
\text { d'ceufs fécondés }\end{array}$} & \multirow[b]{2}{*}{$\%$} \\
\hline & & & $\begin{array}{c}\text { Noyaux } \delta \\
\text { et } q \text { ayant } \\
\text { une structure } \\
\text { normale }\end{array}$ & $\begin{array}{l}\text { Noyau } \delta \\
\text { ayant une } \\
\text { structure }-1 \\
\text { dense à cóté } \\
\text { du noyau }+\end{array}$ & & \\
\hline LM $\ldots \ldots \ldots$ & 7 & 7 & & & i & 0 \\
\hline LN $\ldots \ldots \ldots$ & f) & 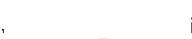 & & 5 & 5 & 83,3 \\
\hline $\mathrm{LQ} \ldots \ldots$ & 7 & 7 & & & & 0 \\
\hline $\mathrm{LO}+\mathrm{LP} \ldots$ & 8 & 8 & & & & 0 \\
\hline LS ........ & 7 & 1 & 4 & 2 & 6 & 85,7 \\
\hline $\mathrm{LT} \ldots \ldots$ & 9 & 1 & 2 & 6 & 8 & 88,9 \\
\hline \multirow[t]{2}{*}{$\mathrm{LU}$} & 5 & 2 & & 3 & 3 & 60 \\
\hline & 49 & 26 & 6 & 16 & 22 & 44,9 \\
\hline
\end{tabular}

L'analyse cytologique a confirmé que dans tons les cas de fécondation, même lorsque le noyau mâle avait une structure normale, le deuxième globule polaire n'avait jamais été émis.

D'après les observations que nous avons pu faire, il semble que l'évolution de la 
chromatine mâle dans l'œuf s'effectue principalement de deux façons : lorsque le pronucléus mâle a une structure normale il peut y avoir fusion des deux chromatines mâle et femelle pour former un noyau triploïde, mais la seule preuve sur laquelle nous puissions nous appuyer est la présence dans certains œufs, d'un noyau de très grande taille, plus grand qu'un noyau diploïde normal.

D'autre part, lorsque le noyau mâle est ponctiforme, la chromatine mâle ne participe pas à la formation de la plaque équatoriale et reste à côté du fuseau. Elle passe ensuite dans 1'un des deux blastomères formés.

Lorsqu'on laisse les ceufs en culture pendant des temps plus longs, de 20 à 24 heures, la plupart des aufs se divisent. Cependant la segmentation est très irrégulière et il se forme souvent de faux blastomères surnuméraires. Il peut aussi y avoir plusieurs noyaux dans un seul blastomère, les autres étant dépourvus de chromatine, ou plusieurs noyaux dans plusieurs blastomères, que les œufs soient fécondés ou non, alors que les œufs parthénogénétiques qui n’ont pas été en contact avec les spermatozoïdes se divisent normalement.

Ainsi lorsque les œufs se développent en l'absence de sperme, la segmentation est normale, mais lorsque les cufs sont inséminés, la segmentation est irrégulière. Les spermatozoïdes présents dans le milieu exercent donc une action défavorable sur leur développement.

\section{DISCUSSION}

Les résultats de nos expériences confirment que le traitement le plus efficace pour obtenir l'activation parthénogénétique avec formation constante d'un noyau femelle diploïde suivie d'une segmentation régulière de l'œuf consiste à placer les ovules à I0 ${ }^{\circ} \mathrm{C}$ pendant 24 heures (ChANG, I953).

Chang a obtenu après refroidissement et transfert de $4 \mathrm{I} œ u$ fs dans les trompes de Lapines hôtes, pendant 6 à Io heures la reconstitution de noyau dans 38 de ces oufs, soit 93 p. roo. 35 de ces 4 I œufs n'avaient qu'un seul globule polaire, 6 œufs avaient émis leur deuxième globule polaire. Nous avons obtenu un pourcentage d'activation analogue (97 p. Ioo) mais sans aucune émission de deuxième globule polaire.

Il est également possible d'obtenir l'activation par refroidissement brutal mais limité, à $0^{\circ} \mathrm{C}$, comme 1'ont signalé Pincus et Shapiro (I940), cependant, nous avons enregistré de grandes différences d'une expérience à l'autre ; c'est ainsi que pour un refroidissement de 60 secondes, sur 48 ovocytes provenant de 7 Lapines, 36 ont reconstitué un pronucléus ( 75 p. roo) et 35 ont émis leur deuxième globule polaire, tandis que les ovocytes provenant d'une autre série de Lapines et traités de façon apparemment identique, n'ont présenté aucun signe d'activation.

L'instabilité de la réponse laisse penser qu'un autre facteur que le froid a probablement pu intervenir. Nos recherches pour en préciser la nature : hypertonie, hypotonie, combinées à 1'action du froid ont échoué. Il est possible que des facteurs génétiques interviennent. Étant donné la provenance des Lapines utilisées, il ne nous a pas été possible de sonder cette hypothèse.

Aussi ces variations dans les résultats ne nous ont pas permis d'utiliser le refroidissement brutal pour contrôler la fécondabilité des œufs ainsi activés. Nous avons dû limiter notre étude aux ovocytes activés à I $0^{\circ} \mathrm{C}$ et possédant $2 n$ chromosomes femelles. 
Notre travail montre la possibilité de féconder dans une très large proportion des ovocytes préalablement activés et nous sommes parvenus à un pourcentage de $29 \mathrm{p}$. Ioo de fécondation in vitro et de $45 \mathrm{p}$. Ioo in vivo, la différence trouvée étant semblable à celle observée dans la fécondation des ovocytes vierges in vitro et in vivo (ThrBaULT et Dauzier, r96r).

La proportion d'œufs activés fécondés que nous avons eu est plus grande que celle qui avait été donnée par Austin (I7 p. Ioo sur des œufs de Ratte). Chang (I952) avait obtenu 78 p. Ioo de fécondation d'œufs traités par le froid, mais la proportion d'œufs réellement activés n'étant que de 57 p. Ioo, une partie des œufs fécondés provenant d'ovocytes non activés, la proportion réelle d'ovocytes activés et fécondés reste donc inconnue dans son expérience, et inférieure à 57 p. Ioo.

Chez la Lapine, 1'activation par l'agent parthénogénétique n'est pas comparable à l'activation đue à la pénétration du spermatozoïde. La rétention du deuxième globule polaire est déjà une différence suffisante car ce phénomène se produit rarement dans la fécondation normale de l'œuf de Lapine ('Thibaul'T, I962).

Mais on constate également que l'œuf parthénogénétique reste sensible à l'action lytique à distance, du spermatozoïde, comme l'est l'œuf vierge, alors que l'œuf fécondé ne l'est plus ('Thibault et Dauzier, Ig6r). Enfin la fécondation de ces œufs parthénogénétiques par un spermatozoïde, déclenche dans la proportion normale le blocage de la pénétration de spermatozoïdes surnuméraires; la pénétration du spermatozoïde fécondant est donc capable d'achever une action commencée par un agent activant.

L'activation parthénogénétique de l'ovocyte de la Lapine n'aurait donc de commun avec l'activation par le spermatozoïde que le déclenchement de la segmentation, mais non tous les caratères que l'on trouve dans la fécondation, notamment la résistance à certaines enzymes (spermolysine pour l'ovocyte de Lapine, enzymes de l'hépatopancréas pour l'œuf de Grenouille) et le blocage de la polyspermie c'està-dire 1'infécondabilité, puisque près de $50 \mathrm{p}$. Ioo des ovocytes parthénogénétiques sont encore fécondables.

Ginsburg (I96I) a observé sur des cufs de Truite et d'Esturgeon une perte de fécondabilité des œufs par piqûre. Le pourcentage d'œufs fécondés diminue quand l'intervalle piqûre-insémination augmente. Lorsque la piqûre est faite au pôle animal de l'œuf, ro p. Ioo des œufs sont encore fécondables 5 secondes après l'activation, mais après Io secondes aucun œuf ne peut être fécondé. Si la piqûre est faite au pôle végétatif, après un intervalle de I minute, $80 \mathrm{p}$. Ioo des oufs sont encore fécondables tandis qu'après 4 minutes, aucun œuf n'est fécondé. La réaction corticale gagne progressivement la région micropylaire avec élimination de granules; tant que cette vague n'a pas atteint la région micropylaire, les œufs sont encore fécondables.

Dans le cas des ovules de Lapine, les phénomènes sont très différents puisque nous avons vu que le temps minimum nécessaire à la pénétration du spermatozoïde est d'environ 2 heures or le pronucléus femelle qui se constitue après mise en culture, est déjà pleinement formé après 2 heures et parfois même après I heure. A ce moment, $1 \mathrm{e}$ spermatozoïde fécondant n'a pas encore pénétré. On se trouve donc dans une situation exactement inverse de la situation naturelle, dans laquelle la formation du pronucléus mâle précède celle du pronucléus femelle puisque la tête mâle évolue déjà pendant l'émission du deuxième gobule polaire. Lorsque les œufs activés sont replacés dans 
les conditions naturelles de fécondation, la pénétration des spermatozoïdes est plus rapide, mais la différence obtenue dans les pourcentages de fécondation d'œufs activés in vitro (29 p. Ioo) et in vivo (45 p. Ioo) tient à l'imperfection de la technique in vitro comme le montre la comparaison des résultats obtenus pour la fécondation d'œufs vierges ( 76 p. Ioo et $95 \mathrm{p}$. Ioo) et non à une pénétration plus facile, par suite de la lenteur de la réaction propre. Les échelles de temps en cause sont des minutes ou des heures et non des secondes comme dans l'expérience de GinsburG.

La pénétration tardive du spermatozoïde permet d'observer un fait d'une portée plus générale : l'évolution du noyau dépend de l'état du cytoplasme dans lequel il baigne. Lorsque le spermatozoïde pénètre tôt dans le cytoplasme, il forme un pronucléus presque normal, seule la taille reste inférieure à celle du pronucléus femelle, alors qu'en général, la taille du pronucléus mâle est plus grande que celle du noyau femelle. Il y a alors essai de fusion du noyau femelle diploïde et du noyau mâle haploïde, mais l'évolution ne se poursuit pas normalement. Les segmentations deviennent rapidement abortives, et il se forme des blastomères sans chromatine. Cette évolution est donc bien différente de celle d'œufs également triploïdes, mais par dispermie, puisque AUSTIN et BRADEN (I95.3) ont observé dans le cas de polyspermie d'œufs de Rattes, la fusion de tous les noyaux pour former un noyau triploïde. Les divisions de segmentations ne présentaient aucune particularité au moins jusqu'au stade 8 blastomères. Piko (I958) a confirmé chez le Rat la participation de chacun des noyaux spermatiques à la formation du noyau amphimixique. La découverte d'embryons de Truie triploïdes (Bomser-HelmREICH, I96I) à partir d'œufs fécondés tardivement et dont le tiers environ possède trois noyaux ('Thibaui,T, I959) montre que la cause des divisions abortives n'est pas nécessairement liée à l'état triploïde.

Lorsque la pénétration du spermatozoïde est plus tardive, c'est-à-dire dans les œufs dont le noyau femelle et le cytoplasme ovulaire, ont un âge que l'on peut considérer comme égal à trois heures au moins, l'évolution de la chromatine mâle ne peut plus se faire et le pronucléus mâle reste à l'état ponctiforme. Ce matériel chromatique ne participe à pas la division nucléaire, et semble destiné à être éliminé, mais il perturbe les phénomènes de division et la segmentation est abortive. On peut assimiler cet état à celui que BATAILlon (I9Io) a observé par fécondations croisées chez des Batraciens.

Dans les œufs polyspermiques, observés après activation parthénogénétique, les pronucléi mâles ont tous une structure normale et identique, ce qui indique une pénétration précoce et simultanée dans le cytoplasme ovulaire. Chacun des pronucléi mâles a une taille analogue à celle des pronucléi mâles des cufs monospermiques, alors qu'au contraire AUSTIN et BRADEN (I953) constatent que les pronucléi des œufs polyspermiques sont toujours plus petits que ceux des oufs normaux et que leur volume total reste à peu près identique à celui d'un seul pronucléus.

La polyspermie dans les œufs activé, ne se produit que dans 7 p. Ioo des oufs fécondés, c'est donc qu'il y a une seconde réaction propre de l'œuf, au moment de la pénétration du spermatozoïde fécondant, beaucoup plus efficace que celle déclenchée initialement par le refroidissement. 


\author{
SUMMARY \\ POSSIBILITY OF FERTILIZATION \\ OF PARTHENOGENETICALLY ACTIVIATED RABBIT EGGS
}

The fertility of the rabbit oocyte after activation by cold had been studied and the reaction of the parthenogenetic egg was compared with that of the normally fertilized egg. In this experiment $43^{\circ}$ rabbits from non-selected breeders were used.

Cooling the oocyte of the rabbit in vitro to $0^{\circ} \mathrm{C}$ for $\mathrm{I}$ minute resulted in the emission of the second polar globule and the formation of a haploid pronucleus in about one-half the cases under experimental treatment (table 2).

Cooling to $10^{\circ} \mathrm{C}$ for 24 hours produced an activation of all the oocytes treated, the formation of a diploid nucleus without the emission of the second polar globule and a very regular division (table I).

The regular activation of the oocytes in this manner enabled a study of the possibility of their subsequent fertilization to be undertaken.

The percentage of oocytes activated and fertilized rose to $29 \mathrm{p}$. I00 in vitro and 45 p. 100 after transplanting in vivo (tables 3 and 4 ).

This work confirmed the results already reported for the rat and the rabbit and, taking into consideration the precision permitted by the in vitro techniques, it should be considered that Bataillon's hypothesis of the inability of the activated frog egg to be fertilized could not be applied to the oocyte of the rabbit, because the parthenogenetic activation of the latter stimulated only the segmentation mechanisms and not systematically the specific reactions of the activated egg, i. e. emission of the second polar globule, resistance to the action of certain enzymes, prevention of polyspermy.

The evolution of these eggs, fertilized after parthenogenetic activation, always gave rise to abortive segmentation, whatever the method of development of the fertilizing sperm cell had been. When the male pronucleus attempted to unite with that of the female, anomalies arose as from the first division : the production of numerous sub-nuclei and of supernumenary blastomeres with or without nucleus. When, as the result of a late entry, the sperm cell did not develop, the first division could be normal, but those following were disturbed by the presence of the male chromatin.

Only 7 p. Ioo of the activated and fertilized eggs were polyspermic, a fact which indicated the presence of a veritable activation reaction at the moment of penetration of the fertilizing sperm cells into almost all the eggs.

\title{
RÉFÉRENCES BIBLIOGRAPHIQUES
}

Almquist J. O., Flipse R. J., Tilacker D. L., 1954. Diluters for bovine semen. J. Dairy Sci., 37, I 203 1307 .

Austin C. R., Braden A. W. H., I953. Polyspermy in the rat and rabbit. Austr. J. Biol. Sci., 6, 674-692.

AUstin C. R., Braden A. W. H., I954. Induction and inhibition of the second polar division in the rat egg and subsequent fertilization. Austr. J. Biol. Sci., 7, 195-210.

Austin C. R., 1956. Activation of eggs by hypothermia in rats and hamsters. J. Exp. Biol., 33, 338-347.

Bataillon E., Igro. Le problème de la fécondation circonscrit par l'imprégnation sans amphimixie et la parthogenèse traumatique. Arch. Zool. Exp., 6, Iо I-I 35.

Bataillon E., I9r2. La parthogenèse des amphibiens et la "fécondation chimique "de Locb (étude analytique). Ann. Sci. nat. $9^{\mathrm{e}}$ série. 249-304.

Bataillon E., I929. Analyse de la fécondation par la parthogénèse expérimentale. Roux Arch. Enters Mech. Org. II.5.

Bomsel-Helmreich 0 ., ig6r. Hétéroploïdie expérimentale chez la truie. $4^{\mathrm{e}}$ Congr. intern. Reprod. Insém. art. La Haye.

Braden A. W. H., 1953. Distribution of sperms in the genital tract of the female after coitus. Austr. J. Biol. Sci., 6, 693-704. 
Braden A. W. H., Austin C. R., David H. A., 1954. The reaction of the zona pellucida to sperm penetration. Austr. J. Biol. Sci, 7, 391-409.

Cinang M. C., 1952. Fertilizability of rabbit ova and the effects of temperature in vitro on their subsequent fertilization and activation in vivo. J. Exp. Zool., 121, 351-382.

Chang M. C., 1953. Storage of unfertilized rabbit ova subsequent fertilization and the probability of normal development. Nature, 172, 353 .

Cinang M. C., I954. Development of parthenogenetic rabbit blastocysts induced by low temperature storage of unfertilized ova. J. Exp. Zool., 125, 127-1 50.

Cinang M. C., 1957. Natural occurence and artificial induction of parthenogenatic cleavage of ferret ova. Anat. Rec., 128, $187-200$.

GinsBurg A.S., 196I. The block to polyspermy in sturgeon and trout with special reference to the role of cortical granules (alveloli). J. Embryol. Exper. Morphol., 9, 173-190.

Hammond J., 1949. Recovery and culture of tubal mouse ova. Nature, 163, 28.

Piko L., 1958. Étude de la polyspermie chez le rat. C. R. Soc. Biol., 152, 1356.

Piko K., 196r. La polyspermie chez les animaux. Ann. Biol. Anim. Bioch. Biophys., 1, 324-384.

Pixcus G., Silapiro H., I940. Further studies on the parthenogenetic activation of rabbit eggs. Proc. Nat. Acad. Sci. Wash., 26, 163-165.

P'trshottam N., Pincus G, ig6r. In vitro cultivation of Mammalian eggs. Anat. Rec., 140, 5 I-55.

Thiballt C., 1949. L'œuf des Mammifères. Son développement perthénogénétique. Ann. Sci. Nal. Zool., 11, I $36-219$,

Thibault C., I959. Analyse de la fécondation de l'œuf de truie après accouplement ou insémination artificielle. Coll. Reprod. Insem. art., Ann. Zootech. supp., 165-177.

Thibault C., Daczier L., Wintemberger S., 1954. La fécondation in vitro de l'ouf de lapine. $C: R$. Soc. Biol., 148, 789 .

Tinbault C., Dalzier L., I96r. Analyse des conditions de la fécondation in vitro de l'oeuf de la lapine. Ann. Biol. anim. Bioch. Biophys., 1, 277-294. 